\title{
Intracellular calcium oscillations and activation in horse oocytes injected with stallion sperm extracts or spermatozoa
}

\author{
S. J. Bedford ${ }^{1}$, M. Kurokawa ${ }^{1}$, K. Hinrichs ${ }^{2}$ and R. A. Fissore ${ }^{1 *}$ \\ ${ }^{1}$ Department of Veterinary and Animal Sciences, Paige Laboratory, University of Massachusetts, \\ Amherst, MA 01003-9286, USA; and ${ }^{2}$ Department of Physiology and Pharmacology, College of \\ Veterinary Medicine, Texas A\&M University, College Station, TX 77843-4466, USA
}

In oocytes from all mammalian species studied to date, fertilization by a spermatozoon induces intracellular calcium $\left(\left[\mathrm{Ca}^{2+}\right]_{\mathrm{i}}\right)$ oscillations that are crucial for appropriate oocyte activation and embryonic development. Such patterns are species-specific and have not yet been elucidated in horses; it is also not known whether equine oocytes respond with transient $\left[\mathrm{Ca}^{2+}\right]_{i}$ oscillations when fertilized or treated with parthenogenetic agents. Therefore, the aims of this study were: (i) to characterize the activity of equine sperm extracts microinjected into mouse oocytes; (ii) to ascertain in horse oocytes the $\left[\mathrm{Ca}^{2+}\right]_{i}$-releasing activity and activating capacity of equine sperm extracts corresponding to the activity present in a single stallion spermatozoon; and (iii) to determine whether equine oocytes respond with $\left[\mathrm{Ca}^{2+}\right]_{i}$ transients and activation when fertilized using the intracytoplasmic sperm injection (ICSI) procedure.
The results of this study indicate that equine sperm extracts are able to induce $\left[\mathrm{Ca}^{2+}\right]_{i}$ oscillations, activation and embryo development in mouse oocytes. Furthermore, in horse oocytes, injection of sperm extracts induced persistent $\left[\mathrm{Ca}^{2+}\right]_{i}$ oscillations that lasted for $>60 \mathrm{~min}$ and initiated oocyte activation. Nevertheless, injection of a single stallion spermatozoon did not consistently initiate $\left[\mathrm{Ca}^{2+}\right]_{i}$ oscillations in horse oocytes. It is concluded that stallion sperm extracts can efficiently induce $\left[\mathrm{Ca}^{2+}\right]_{i}$ responses and parthenogenesis in horse oocytes, and can be used to elucidate the signalling mechanism of fertilization in horses. Conversely, the inconsistent $\left[\mathrm{Ca}^{2+}\right]_{i}$ responses obtained with sperm injection in horse oocytes may explain, at least in part, the low developmental success obtained using ICSI in large animal species.

\section{Introduction}

Assisted reproduction technologies have gained wide acceptance in humans and in domestic animal species. In horses, the success of technologies such as intracytoplasmic sperm injection (ICSI) has been limited and this is thought to be due primarily to inadequate oocyte activation and in vitro embryo culture systems (Kato et al., 1997; Li et al., 2000, 2001). With respect to oocyte activation, two reports have specifically addressed parthenogenetic methods of activation in horses (Hinrichs et al., 1995; Choi et al., 2001), but the underlying signalling mechanisms leading to activation of equine oocytes have not been characterized.

In oocytes from all mammalian species studied to date, fertilization by a spermatozoon induces a series of species-specific increases in intracellular $\mathrm{Ca}^{2+}$ concentration $\left(\left[\mathrm{Ca}^{2+}\right]_{\mathrm{i}}\right)$ that are crucial for oocyte activation (Fissore et al., 1992; Kline and Kline, 1992; Nakada et al., 1995). These fertilization-associated oscillations are responsible for downregulation of maturation-promoting

*Correspondence

Email: rfissore@vasci.umass.edu factor (MPF), which allows resumption of meiosis, cortical granule exocytosis and block to polyspermy, pronuclear formation, and initiation of embryonic cleavage, all of which are events in egg activation (Kline and Kline, 1992; Carroll, 2001). Furthermore, recent research indicates that the initiation and modulation of these $\left[\mathrm{Ca}^{2+}\right]_{i}$ Oscillations may affect not only preimplantation, but also postimplantation, embryonic development in mammalian species (Ozil and Huneau, 2001).

The exact mechanism by which a spermatozoon triggers $\left[\mathrm{Ca}^{2+}\right]_{i}$ oscillations is the subject of intense research, and although both membrane-mediated (receptor) and fusion-mediated (sperm factor) pathways have been postulated as initiators of $\left[\mathrm{Ca}^{2+}\right]_{i}$ oscillations, there is more evidence for a role of an activating factor introduced by the spermatozoon (for reviews, see Swann, 1996; Fissore et al., 1998). Despite the uncertainty of how oscillations are initiated, it is widely accepted that fertilization results in activation of the phosphoinositide pathway, with production of inositol 1,4,5-triphosphate $\left(\mathrm{IP}_{3}\right)$ by the enzymatic action of phospholipase C (PLC), and the subsequent release of $\left[\mathrm{Ca}^{2+}\right]_{i}$ from the endoplasmic reticulum (Carroll, 2001). Further investigation into the role of PLC isoforms as the 
initiators of $\left[\mathrm{Ca}^{2+}\right]_{i}$ oscillations has led to the recent identification of a sperm-specific PLC (PLC $\xi$ ) as the putative sperm-derived oocyte activating factor (Saunders et al., 2002). Furthermore, a homologue of PLC $\xi$ has been found in mouse, human and monkey spermatozoa (Cox et al., 2002).

As well as fertilization, oocyte activation can also be initiated parthenogenetically. The most commonly used treatments, electroporation, $\mathrm{Ca}^{2+}$ ionophores and ethanol, are all known to induce a single $\left[\mathrm{Ca}^{2+}\right]_{i}$ increase in oocytes (Fissore and Robl, 1992, 1993; Collas et al., 1993; Nakada and Mizuno, 1998) and thus are unlikely to support activation and embryonic development at rates similar to those observed at fertilization. Therefore, ethanol and ionomycin are often used in combination with inhibitors of protein phosphorylation (for example, 6-DMAP) or synthesis (for example, cycloheximide) to optimize rates of oocyte activation for assisted reproduction in cows and horses (Presicce and Yang, 1994; Hinrichs et al., 1995; Chung et al., 2000; Choi et al., 2001; Knott et al., 2002). Other parthenogenetic treatments, such as thimerosal, strontium chloride, $\mathrm{IP}_{3}$ or adenophostin, induce multiple $\left[\mathrm{Ca}^{2+}\right]_{i}$ responses in mammalian oocytes and yield rates of activation more comparable to those observed at fertilization (Fissore and Robl, 1993; Fissore et al., 1995; Nakada and Mizuno, 1998; Sato et al., 1998; Jones and Nixon, 2000), although the difficulty of administration and some undesirable side effects have limited their use.

A more novel and possibly more physiological procedure for activation of mammalian oocytes is the injection of cytosolic sperm extracts, also referred to as sperm factor (SF). Previous reports show that injection of SF stimulates the phosphoinositide pathway resulting in a pattern of $\left[\mathrm{Ca}^{2+}\right]_{i}$ oscillations similar to that observed at fertilization (Wu et al., 1997, 1998a, 2001; Knott et al., 2002), thereby further supporting the theory that a molecule introduced by the spermatozoon at the time of gamete fusion is the trigger for oscillations and subsequently for oocyte activation (Fissore et al., 1998). Furthermore, injection of either homologous or heterologous SF supports oocyte activation and embryonic development in mouse, rabbit, cow and pig oocytes (Stice and Robl, 1990; Wu et al., 1997, 1998b; Machaty et al., 2000; Knott et al., 2002), indicating that a highly conserved mechanism or molecule is probably responsible for the initiation and persistence of $\left[\mathrm{Ca}^{2+}\right]_{\mathrm{i}}$ oscillations in mammalian species.

Recently, crude sperm extracts obtained from the supernatant of frozen-thawed stallion sperm lysates have been used to activate equine oocytes subjected to nuclear transfer (Choi et al., 2002a). However, the $\left[\mathrm{Ca}^{2+}\right]_{i}$ responses produced by these fractions have not been characterized, and it has not been demonstrated whether equine oocytes respond with $\left[\mathrm{Ca}^{2+}\right]_{i}$ transients to parthenogenetic treatments or fertilization. Therefore, the aims of the present study were: (i) to determine the
$\left[\mathrm{Ca}^{2+}\right]_{i}$-releasing and parthenogenetic activity of stallion sperm extracts microinjected into mouse oocytes; (ii) to ascertain whether stallion sperm extracts would induce $\left[\mathrm{Ca}^{2+}\right]_{i}$ oscillations and activation in metaphase II horse oocytes; and (iii) to determine whether horse oocytes would undergo fertilization-like $\left[\mathrm{Ca}^{2+}\right]_{i}$ oscillations after ICSI.

\section{Materials and Methods}

\section{Recovery and culture of mouse oocytes}

Two strains of mice, CD1 and B6D2F1, were used for microinjection and ICSI experiments, respectively, as oocytes of the B6D2F1 strain are known to sustain higher rates of survival after sperm injection (Kimura and Yanagimachi, 1995). Ovaries were superstimulated by injection of 5 iu eCG (Sigma Chemical Co., St Louis, MO), followed $48 \mathrm{~h}$ later by injection of 5 iu hCG (Sigma). Metaphase II mouse oocytes were obtained from the oviducts of 4-16-week-old female mice that were killed at about $14 \mathrm{~h}$ after hCG administration. After retrieval of the oocytes, cumulus cells were removed by incubation for 3-5 min in bovine testis hyaluronidase in Dulbecco's PBS (DPBS; $0.1 \%(w / v)$; Sigma). Oocytes showing no evidence of degeneration and that had extruded the first polar body were used for microinjection or ICSI. Oocyte incubation was performed in microdroplets of potassium simplex optimized medium (KSOM; Specialty Media, Phillipsburg, NJ) under paraffin oil at $36.5^{\circ} \mathrm{C}$ in a humidified atmosphere with $5 \% \mathrm{CO}_{2}$.

\section{Recovery, in vitro maturation (IVM) and culture of equine oocytes}

Equine cumulus-oocytes complexes (COCs) for IVM were obtained by scraping the follicular walls of ovaries collected from an abattoir. Oocytes with expanded cumuli (meiotically competent oocytes; Hinrichs and Schmidt, 2000) were placed into $1 \mathrm{ml}$ equilibrated maturation medium (TCM199 with Earle's salts; Gibco Life Technologies, Inc., Grand Island, NY) supplemented with $5 \mu \mathrm{U} \mathrm{FSH} \mathrm{ml}{ }^{-1}$ (Sioux Biochemical Inc., Sioux Center, IA), 10\% FBS and $25 \mu \mathrm{g}$ gentamycin $\mathrm{ml}^{-1}$. The vial containing the oocytes was sealed and packaged into a commercial incubator (Minitube of America, Inc., Verona, WI) for overnight shipment at $38^{\circ} \mathrm{C}$. Upon arrival, the oocytes were placed in microdroplets of the same medium under light mineral oil in an incubator at $38^{\circ} \mathrm{C}$ in $5 \% \mathrm{CO}_{2}$ in humidified air to continue maturation as required for individual experiments (that is, 24 or $42 \mathrm{~h}$ after the time at which the oocytes had been placed in the incubator for shipment). After the appropriate maturation period, the oocytes were denuded from their cumulus cells by repeated pipetting in bovine testis hyaluronidase in DPBS $(0.1 \%(\mathrm{w} / \mathrm{v})$; Sigma). Oocytes with intact cytoplasmic membranes with no signs of degeneration or 
fragmentation and with a visible perivitelline space were selected for micromanipulation. After microinjection and monitoring, equine oocytes were incubated in culture medium but without $\mathrm{FSH}$ at $38^{\circ} \mathrm{C}$ in $5 \% \mathrm{CO}_{2}$ in humidified air for an additional 20-24 h before evaluation of activation status.

\section{Preparation of equine sperm extracts (eSF)}

Pooled ejaculates from two stallions of proven fertility were used to prepare eSF following a procedure similar to that previously described for pig sperm extracts (pSF; Wu et al., 1997, 1998a). In brief, pooled semen samples were washed twice with TL-Hepes medium and the sperm pellet was resuspended in a solution containing $75 \mathrm{mmol}$ $\mathrm{KCl} \mathrm{I}^{-1}, 20 \mathrm{mmol} \mathrm{Hepes}^{-1}, 1 \mathrm{mmol}$ EDTA I ${ }^{-1}, 10 \mathrm{mmol}$ glycerophosphate $\mathrm{I}^{-1}, 1 \mathrm{mmol}$ dithiothreitol $\mathrm{I}^{-1}, 200$ $\mu \mathrm{mol}$ phenylmethylsulphonyl fluoride (PMSF) $\mathrm{I}^{-1}$, $10 \mu \mathrm{g}$ pepstatin $\mathrm{ml}^{-1}$ and $10 \mu \mathrm{g}$ leupeptin $\mathrm{ml}^{-1}, \mathrm{pH}$ 7.0. The sperm suspension was subjected to a freeze-thaw cycle by submerging it in liquid nitrogen at $-196^{\circ} \mathrm{C}$ for $5 \mathrm{~min}$ and then thawing it at room temperature, and the suspension was sonicated (XL2020; Heat Systems Inc., Farmingdale, NY) at $4^{\circ} \mathrm{C}$ for $10-20$ min (or until head-tail separation was evidenced by evaluation of a sample by contrast microscopy). The lysate was centrifuged at $10000 \mathrm{~g}$ and the supernatant was collected for ultracentrifugation at $100000 \mathrm{~g}$ for $1 \mathrm{~h}$ at $4{ }^{\circ} \mathrm{C}$. Ultrafiltration membranes (Centriprep-30; Amicon, Beverly, $\mathrm{MA}$ ) were used to wash the supernatant obtained from ultracentrifugation and to concentrate the protein extracts. Crude extracts were slowly mixed with ammonium sulphate to $50 \%$ saturation and the precipitate was collected by centrifugation $\left(10000 \mathrm{~g}, 15 \mathrm{~min}, 4^{\circ} \mathrm{C}\right)$. The pellets were stored at $-80^{\circ} \mathrm{C}$ to resume sperm extract preparation at a later time before use.

For microinjection purposes, the stored precipitate was resuspended and washed in injection buffer (75 mmol KCl I-1, $20 \mathrm{mmol}$ Hepes $\mathrm{I}^{-1}, \mathrm{pH} \mathrm{7.0)}$ and protein was concentrated in ultrafiltration membranes (Centriprep-30 and Centricon-30; Amicon). Final protein concentrations were assessed using a bicinchoninic acid protein assay kit (Sigma) for protein determination. In brief, samples with known protein concentrations and eSF aliquots were incubated at $37^{\circ} \mathrm{C}$ for $30 \mathrm{~min}$ in a reagent containing 1 part copper sulphate pentahydrate $(4 \%(\mathrm{w} / \mathrm{v})$ solution) and 50 parts bicinchoninic acid solution (B-9643). Absorbance of the samples was determined in microplates $(562 \mathrm{~nm})$ using MRX ${ }^{\mathrm{TC}}$ revelation software (Dynex Technologies, Inc., Chantilly, VA). Protein concentrations in eSF aliquots were extrapolated from a plot obtained with standard samples.

\section{Microinjection procedure}

Microinjection was performed as described by $\mathrm{Wu}$ et al. (1998a,b). In brief, denuded metaphase II mouse or equine oocytes were microinjected using a Nikon Diaphot microscope (Nikon Inc., Garden City, NY) and Narishige manipulators (Medical Systems Corp., Great Neck, NY). Injection pipettes containing $0.5 \mathrm{mmol}$ fura2 dextran $\mathrm{I}^{-1}$ (fura-2D; Molecular Probes; Eugene, OR) or appropriate concentrations of pSF, eSF or adenophostin were advanced into the cytoplasm of each individual oocyte and an appropriate volume of the reagent was injected by pneumatic pressure (PLI-100 Picoinjector; Harvard Apparatus; Cambridge, MA). The injection volume ranged from $5 \mathrm{pl}$ to $10 \mathrm{pl}$ in mouse oocytes and from $15 \mathrm{pl}$ to $20 \mathrm{pl}$ in equine oocytes.

For microinjection of mouse oocytes, the concentration of eSF $\left(0.25\right.$ or $0.50 \mu g \mathrm{gl}^{-1}$ ) was chosen on the basis of results from previous research in our laboratory, in which use of similar concentrations of equally prepared pSF provided fertilization-like $\left[\mathrm{Ca}^{2+}\right]_{i}$ responses and optimal rates of activation and embryonic development in mouse oocytes (Wu et al., 2001).

\section{ICSI procedure}

ICSI was performed as described by Kimura and Yanagimachi (1995). For ICSI into mouse oocytes, suspensions of washed frozen-thawed or sonicated stallion sperm heads in microinjection buffer were used. Horse oocytes were injected with freshly collected motile spermatozoa washed in DPBS and immobilized by a piezoelectric pulse immediately before injection. Sperm suspensions were mixed with an equal volume of $12 \%(\mathrm{w} / \mathrm{v})$ polyvinylpyrollidine (PVP) and a droplet of this sample was placed on a plastic Petri dish, which served as the injection chamber. Manipulations were performed on an inverted Nikon Diaphot microscope. Injections were performed with a piezomicropipettedriving unit (Piezo drill; Burleigh, Inc., Rochester, NY). The spermatozoon was aspirated into the pipette (tail first for motile spermatozoa) and the tip of the injection pipette was put into contact with the zona pellucida. Several piezo-pulses were applied to advance the pipette through the zona pellucida. Once the pipette passed through the zona, it was advanced against the membrane of the oocyte to the opposite side of its cortex while applying light negative pressure; one or two piezo pulses of lower intensity were applied to penetrate the oocyte membrane, and the sperm head was injected into the cytoplasm surrounded by a minimal amount of fluid.

\section{Fluorescence recordings and determination of $\left[\mathrm{Ca}^{2+}\right]_{i}$}

Fluorescence of fura-2D-loaded oocytes subjected to microinjection or ICSI was monitored as described by $\mathrm{Wu}$ et al. (1997). In brief, the illumination was provided by a $75 \mathrm{~W}$ xenon arc lamp on a Nikon Diaphot microscope equipped with a $\times 40$ UV oil immersion objective (Nikon Inc.). Excitation wavelengths were 340 and $380 \mathrm{~nm}$, and the corresponding emitted light (attenuated 32-fold 
by neutral density filters) was quantified by a photomultiplier tube, which averaged the fluorescence signal over the whole oocyte. The rotation of a filter wheel and a shutter apparatus was controlled by a modified Phoscan 3.0 software program (Nikon Inc.) on a 486 IBMcompatible computer to alternate wavelengths. Fluorescence ratios were obtained every $4 \mathrm{~s}$ and $\left[\mathrm{Ca}^{2+}\right]_{i}$ concentrations were extrapolated from these values in a calibrated system as described by Wu et al. (1998a).

For some experiments, fluorescence values of a group of oocytes were measured simultaneously using the software Image 1/FL (Universal Imaging, Downington, PA). Images were acquired using a SIT camera (Dage-MTI, Michigan City, IN) coupled to an image intensifier (Video Scope International Ltd., Sterling, VA). Fluorescence ratios were obtained every 10-20 s, after $1 \mathrm{~s}$ reading at each wavelength. Data are presented as the ratio of 340:380 fluorescence, which correlates with $\left[\mathrm{Ca}^{2+}\right]_{i}$.

\section{Assessment of oocyte activation status}

For assessment of activation, as well as for experiments investigating in vitro embryonic development, mouse oocytes were observed under a phase contrast microscope for extrusion of the second polar body $(2 \mathrm{~h})$, pronuclear formation (4-6 h), cleavage (24-96 h), and development to the morula and blastocyst stages (96-144 h). At day 6 after microinjection, in selected experiments assessing rates of development, blastocysts were stained with Hoechst 33342 and the number of blastomeres was counted under fluorescence microscopy.

At 20-24 h after microinjection or ICSI, horse oocytes were fixed in saline-buffered formaldehyde with $0.1 \%$ $(\mathrm{v} / \mathrm{v})$ Triton-X100, mounted on a slide with $6.5 \mu \mathrm{l}$ of 9:1 glycerol:PBS containing $2.5 \mu \mathrm{g}$ Hoechst $33258 \mathrm{ml}^{-1}$, and examined using fluorescence microscopy to determine the chromatin configuration. Oocytes were considered activated if one pronucleus was observed. Non-activated oocytes were those in metaphase II or anaphase-telophase configurations. Degenerate oocytes and those in metaphase I were not counted in the assessment of rates of activation.

\section{Protein kinase assays}

Histone $\mathrm{H} 1$ and mitogen-activating protein (MAP) kinase assays were performed as previously described by Fissore et al. (1996) for microinjected mouse oocytes cultured to the pronuclear stage and contemporary noninjected metaphase II oocytes (controls). Myelin basic protein (MBP) was assumed to measure mostly MAP kinase activity as shown by Fissore et al. (1996). Groups of mouse oocytes ( $n=5$ per group) were lysed by several repeated cycles of freezing and thawing in $\mathrm{H} 1$ kinase buffer $\left(80 \mathrm{mmol}\right.$ glycerophosphate $\mathrm{I}^{-1}, 5 \mathrm{mmol}$ EGTA $\mathrm{I}^{-1}$, $15 \mathrm{mmol} \mathrm{MgCl}_{2} \mathrm{I}^{-1}, 1 \mathrm{mmol}$ dithiothreitol I-1, $10 \mu \mathrm{g}$ aprotinin $\mathrm{ml}^{-1}, 10 \mu \mathrm{g}$ leupeptin $\mathrm{ml}^{-1}, 10 \mu \mathrm{g}$ pepstatin $\mathrm{ml}^{-1}$ and $500 \mathrm{nmol}$ cAMP-dependent protein kinase inhibitor $\mathrm{I}^{-1}$ ) and stored at $-80^{\circ} \mathrm{C}$ until use. Kinase reactions were started by adding $5 \mu \mathrm{l}$ of a solution containing $2 \mathrm{mg}$ histone $\mathrm{H} 1 \mathrm{ml}^{-1}$ (type II-S; Sigma), $1 \mathrm{mg}$ MBP $\mathrm{ml}^{-1}$ (Sigma), $0.7 \mathrm{mmol}$ ATP $\mathrm{I}^{-1}$ and $50 \mu \mathrm{Ci}$ $\left[\gamma_{-}{ }^{32}\right.$ P]ATP (Amersham, Arlington Heights, IL) to $5 \mu \mathrm{l}$ of the crude oocyte lysates. The reaction was performed for $30 \mathrm{~min}$ at $30^{\circ} \mathrm{C}$ and terminated by the addition of $5 \mu \mathrm{l}$ SDS sample buffer (Laemmli, 1970). Samples were boiled for $3 \mathrm{~min}$ and loaded into $15 \%(\mathrm{w} / \mathrm{v})$ SDS-polyacrylamide gels. Control samples contained all the components required for the reaction but without the addition of oocytes. Phosphorylation of histone $\mathrm{H} 1$ and MBP was visualized by autoradiography using DuPont's Cronex intensifying screens at $-70^{\circ} \mathrm{C}$ (DuPont, Wilmington, DE). Autoradiographs were scanned and quantified using Adobe Photoshop (Mountain View, CA) and plotted using SigmaPlot software (Jandel Scientific Software, San Rafael, CA). Multiple gel exposures were used to avoid saturation of the quantification system. Kinase activity in microinjected oocytes was normalized to the kinase activity in metaphase II oocytes, which were arbitrarily given the value of 1 .

\section{Statistical analysis}

Values from kinase assays were compared by chisquared analysis, whereas means for activation, embryonic development and $\left[\mathrm{Ca}^{2+}\right]_{i}$ transient data were analysed by one-way ANOVA, followed by comparisons between means applying Student's $t$ test using JMP Inc. software (SAS Institute, Gary, NC). Means were considered significantly different at $P<0.05$.

\section{Results}

Effect of stallion sperm extracts (eSF) on $\left[\mathrm{Ca}^{2+}\right]_{i}$ oscillations in CD1 mouse oocytes

$\mathrm{Wu}$ et al. (1997) showed that injection of pSF into mouse oocytes induces $\left[\mathrm{Ca}^{2+}\right]_{i}$ oscillations similar to those observed at fertilization in this species. The aim of the present study was to investigate whether eSF would have a similar $\left[\mathrm{Ca}^{2+}\right]_{i}$-releasing activity in mouse oocytes. Representative $\left[\mathrm{Ca}^{2+}\right]_{i}$ oscillation profiles for microinjection of 0.25 and $0.50 \mu \mathrm{g} \mathrm{eSF} \mu \mathrm{I}^{-1}$ are shown (Fig. 1) and the results are also summarized (Table 1 ). More mouse oocytes showed $\left[\mathrm{Ca}^{2+}\right]_{i}$ responses when injected with 0.50 rather than $0.25 \mu \mathrm{g}$ eSF $\mu \mathrm{I}^{-1}$. Furthermore, in half of the oocytes injected with the lower concentration of eSF, $\left[\mathrm{Ca}^{2+}\right]_{i}$ oscillations lasted for $<30 \mathrm{~min}$, whereas in all oocytes injected with $0.50 \mu \mathrm{g}$ eSF $\mu \mathrm{I}^{-1}$, transients lasted for $>30$ min and, in most oocytes, for up to 60-120 min. Spike frequency was higher for oocytes injected with the higher concentration of eSF $(P<0.05)$. Overall, $\left[\mathrm{Ca}^{2+}\right]_{i}$ responses obtained with 
(a)

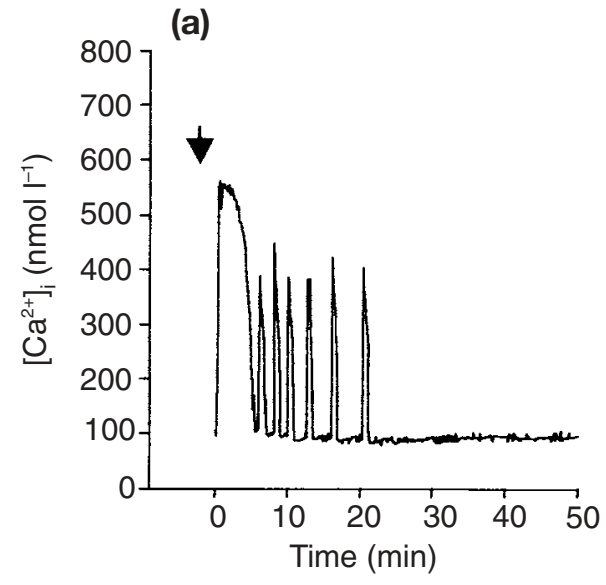

(b)

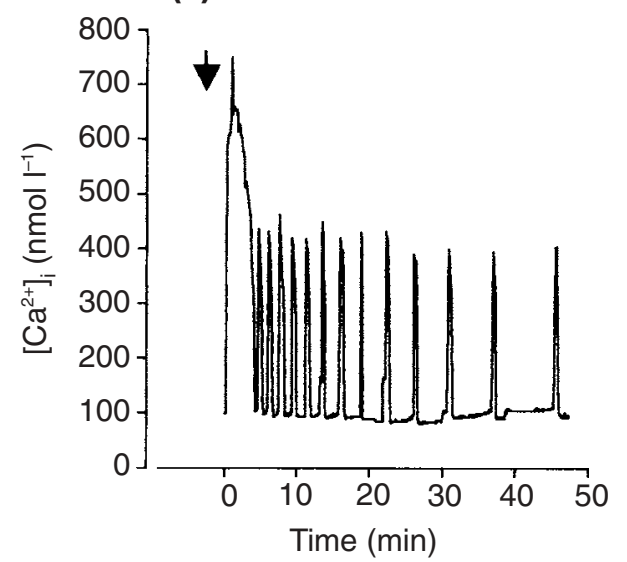

Fig. 1. Representative intracellular $\mathrm{Ca}^{2+}$ concentration $\left(\left[\mathrm{Ca}^{2+}\right]_{\mathrm{i}}\right)$ profiles for metaphase II mouse oocytes microinjected with (a) 0.25 $(n=7)$ or (b) $0.50 \mu \mathrm{g}(n=10)$ equine sperm factor (eSF) $\mu \mathrm{I}^{-1}$. Arrows indicate times of injection.

$0.5 \mu \mathrm{geSF} \mu \mathrm{I}^{-1}$ were similar to those previously reported with pSF in our laboratory and were similar in duration to those reported in mouse oocytes at fertilization (Fissore et al., 1998; Wu et al., 2001). Therefore, $0.5 \mu \mathrm{g}$ eSF $\mu \mathrm{I}^{-1}$ was chosen as the working concentration for subsequent experiments. As expected, injection of buffer alone did not induce $\left[\mathrm{Ca}^{2+}\right]_{i}$ oscillations.

\section{Effect of microinjection of eSF on MPF and MAP kinase downregulation in mouse oocytes}

Fertilization in mammalian oocytes results in the resumption of meiosis, which is accomplished by downregulation of MPF and mitogen-activated protein (MAP) kinases, both of which are responsible for the metaphase II arrest (Whitaker, 1996; Carroll, 2001). Therefore, to test the activity of the stallion sperm extracts further, mouse oocytes were microinjected with $0.5 \mu \mathrm{g}$ eSF $\mu \mathrm{I}^{-1}$ and incubated until the pronuclear stage.
Table 1. Calcium-releasing activity of 0.25 or $0.50 \mu \mathrm{g}$ equine sperm extracts (eSF) $\mu \mathrm{I}^{-1}$ microinjected into metaphase II mouse oocytes

\begin{tabular}{|c|c|c|}
\hline & \multicolumn{2}{|c|}{ eSF } \\
\hline & $0.25 \mu g \mu \mathrm{I}^{-1}$ & $0.5 \mu g \mu I^{-1}$ \\
\hline \multicolumn{3}{|c|}{ Number of eggs oscillating } \\
\hline$>5 \mathrm{~min}$ & $7 / 8$ & $10 / 11$ \\
\hline$>30 \mathrm{~min}$ & $4 / 8$ & $10 / 11$ \\
\hline \multicolumn{3}{|c|}{ Amplitude (nmol I-1) } \\
\hline First spike & $372.1 \pm 57.6$ & $607.1 \pm 57.2^{*}$ \\
\hline Spike $>10$ min & $251.0 \pm 11.7$ & $279.4 \pm 26.6$ \\
\hline \multicolumn{3}{|l|}{ Duration (min) } \\
\hline First spike & $5.43 \pm 0.33^{*}$ & $4.25 \pm 0.25$ \\
\hline Spike $>10 \mathrm{~min}$ & $1.33 \pm 0.11$ & $0.92 \pm 0.04$ \\
\hline \multicolumn{3}{|c|}{ Frequency (number of spikes) } \\
\hline $10-20 \mathrm{~min}$ & $2.3 \pm 0.50$ & $5.2 \pm 0.50^{*}$ \\
\hline
\end{tabular}

Values are mean $\pm \mathrm{SEM}$; results are from at least three replicates.

* Significant difference between groups $(P<0.05)$. (a)

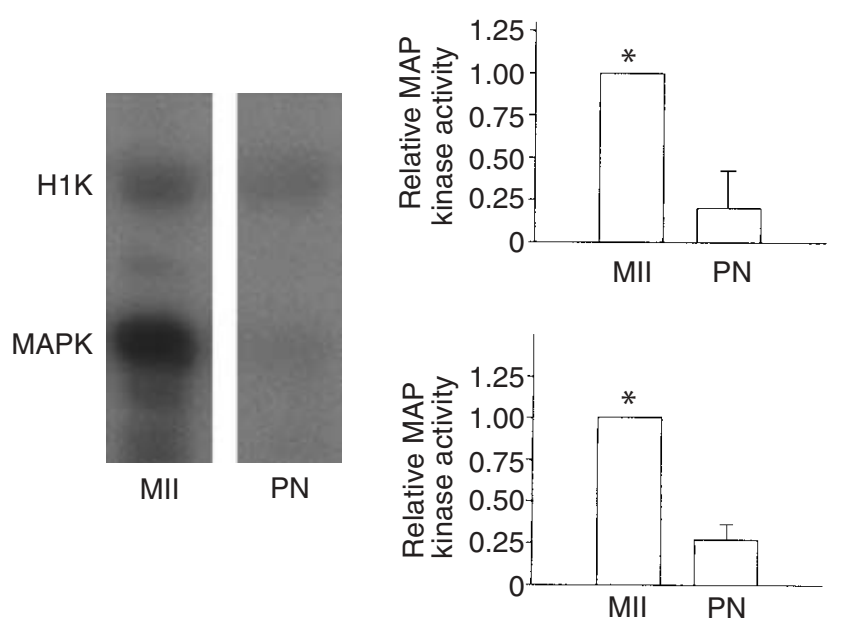

Fig. 2. (a) Kinase assay showing decline of histone $\mathrm{H} 1(\mathrm{H} 1 \mathrm{~K}$; $\mathrm{MPF}$ ) and MAP kinase (MAPK) activities in pronuclear (PN) stage mouse oocytes activated with $0.5 \mu \mathrm{g}$ eSF $\mu \mathrm{I}^{-1}$ compared with uninjected metaphase II (MII) oocytes. (b) Plot for H1 and MAP kinase activities averaged for five replicates. Asterisks indicate significant differences $(P<0.05)$.

Oocytes were collected for kinase assays and the results were compared with metaphase II (uninjected) oocytes incubated under the same conditions. A decrease in MPF and MAP kinase activity was observed in oocytes microinjected with eSF, indicating that eSF is able to promote this decrease in activity and thus support resumption of meiosis in mouse oocytes (Fig. 2a,b). 
Table 2. Activation of mouse oocytes injected with sperm buffer, pig sperm extracts (pSF), adenophostin and equine sperm extracts (eSF)

\begin{tabular}{|c|c|c|c|c|}
\hline & $\begin{array}{l}\text { Number of } \\
\text { oocytes }\end{array}$ & $\begin{array}{l}\text { Extrusion of second polar } \\
\text { body }(2-4 \mathrm{~h})\end{array}$ & $\begin{array}{l}\text { Pronuclear stage } \\
(6-8 \mathrm{~h})\end{array}$ & $\begin{array}{c}\text { Two-cell stage } \\
(24 \mathrm{~h})\end{array}$ \\
\hline Buffer & 10 & $1(10 \pm 0)^{c}$ & $3(30 \pm 0)^{b}$ & $0(0.0 \pm 0)^{b}$ \\
\hline \multicolumn{5}{|l|}{$\mathrm{pSF}$} \\
\hline $0.2 \mu \mathrm{g} \mu \mathrm{I}^{-1}$ & 27 & $26(96 \pm 2.2)^{\mathrm{ab}}$ & $25(92 \pm 7.5)^{\mathrm{a}}$ & $25(92 \pm 7.5)^{\mathrm{a}}$ \\
\hline $0.5 \mu g \mu \mathrm{I}^{-1}$ & 28 & $25(89 \pm 7.2)^{\mathrm{ab}}$ & $27(96 \pm 5.4)^{\mathrm{a}}$ & $26(93 \pm 3.5)^{\mathrm{a}}$ \\
\hline $1.0 \mu g \mu \mathrm{I}^{-1}$ & 45 & $40(88 \pm 3.1)^{\mathrm{b}}$ & $40(88 \pm 3.1)^{\mathrm{a}}$ & $40(88 \pm 5.3)^{a}$ \\
\hline \multicolumn{5}{|l|}{ Adenophostin } \\
\hline $10 \mu \mathrm{mol} \mathrm{I}{ }^{-1}$ & 33 & $28(85 \pm 6.5)^{b}$ & $28(85 \pm 5.0)^{\mathrm{a}}$ & $27(82 \pm 3.5)^{\mathrm{a}}$ \\
\hline $100 \mu \mathrm{mol} \mathrm{I}{ }^{-1}$ & 37 & $35(95 \pm 4.8)^{\mathrm{ab}}$ & $34(92 \pm 7.2)^{\mathrm{a}}$ & $34(92 \pm 4.2)^{\mathrm{a}}$ \\
\hline \multicolumn{5}{|l|}{ eSF } \\
\hline $0.5 \mu g \mu \mathrm{I}^{-1}$ & 42 & $41(98 \pm 1.2)^{\mathrm{a}}$ & $38(90 \pm 4.0)^{\mathrm{a}}$ & $35(83 \pm 3.5)^{\mathrm{a}}$ \\
\hline
\end{tabular}

All data are shown as $n(\% \pm$ SEM).

Results are from at least three replicates.

${ }^{\mathrm{ab}}$ Different superscripts within a column indicate significant differences $(P<0.05)$.

Table 3. Activation and development of mouse oocytes injected with pig sperm extracts (pSF), adenophostin and equine sperm extracts (eSF), and diploidized by incubation in cytochalasin B

\begin{tabular}{|c|c|c|c|c|c|c|}
\hline & $\begin{array}{c}\text { Number of } \\
\text { oocytes }^{\text {a }}\end{array}$ & $\begin{array}{l}\text { Second pronuclear } \\
\text { stage }(6-8 \mathrm{~h})\end{array}$ & Two-cell (24 h) & Morulae (72 h) & $\begin{array}{l}\text { Blastocysts } \\
\quad \text { (day 6) }\end{array}$ & $\begin{array}{c}\text { Number of } \\
\text { cells }(\text { range })^{b}\end{array}$ \\
\hline \multicolumn{7}{|l|}{ pSF } \\
\hline $0.5 \mu g \mu I^{-1}$ & 29 & $29(100 \pm 0)^{\mathrm{c}}$ & $29(100 \pm 0)$ & $23(79 \pm 11.4)$ & $19(66 \pm 16.7)$ & 49 (29-93) \\
\hline \multicolumn{7}{|l|}{ Adenophostin } \\
\hline $10 \mu \mathrm{mol} \mathrm{I}{ }^{-1}$ & 34 & $31(91 \pm 6.8)$ & $30(88 \pm 6.8)$ & $28(82 \pm 9.3)$ & $21(62 \pm 15.4)$ & $45(27-72)$ \\
\hline \multicolumn{7}{|l|}{ eSF } \\
\hline$\left.0.5 \mu g \mu\right|^{-1}$ & 33 & $31(94 \pm 5.9)$ & $25(76 \pm 8.0)$ & $24(73 \pm 4.2)$ & $24(73 \pm 8.8)$ & $41(33-59)$ \\
\hline
\end{tabular}

All data for development are shown as $n(\% \pm \mathrm{SEM})$.

Results are from at least three replicates.

a Number of diploidized oocytes after incubation in $5 \mu \mathrm{g}$ cytochalasin B $\mathrm{ml}^{-1}$ for $4 \mathrm{~h}$.

${ }^{b}$ Mean number of cells in blastocysts after 6 days of culture.

There were no significant differences between means.

\section{Effect of microinjection of eSF on activation and development to the blastocyst stage in CD1 mouse oocytes}

Metaphase II mouse oocytes were microinjected with $0.5 \mu \mathrm{g} \mathrm{eSF} \mu \mathrm{I}^{-1}$ and monitored for pronuclear formation and cleavage to the two-cell stage to characterize further the activity of eSF. Mouse oocytes were also activated by injection of pSF $\left(0.2,0.5\right.$ or $\left.1.0 \mu \mathrm{g} \mu \mathrm{l}^{-1}\right)$ and adenophostin (10 or $100 \mu \mathrm{mol} \mathrm{I}^{-1}$ ), a potent nonhydrolysable agonist of the $\mathrm{IP}_{3}$ receptor, which has been shown to induce $\left[\mathrm{Ca}^{2+}\right]_{i}$ oscillations and activation in mouse oocytes (Sato et al., 1998). There were no differences in the ability of the different agents or concentrations to induce cleavage of mouse oocytes to the two-cell stage (Table 2). In contrast, mouse oocytes injected with microinjection buffer alone did not activate.

Subsequently, metaphase II mouse oocytes were microinjected with eSF $\left(0.5 \mu g \mu \mathrm{I}^{-1}\right)$, pSF $\left(0.5 \mu \mathrm{g} \mu \mathrm{I}^{-1}\right)$ and adenophostin $\left(10 \mu \mathrm{mol} \mathrm{I}^{-1}\right)$, and development to the blastocyst stage was monitored. The oocytes were diploidized by incubation in the presence of cytochalasin $\mathrm{B}\left(5 \mu \mathrm{g} \mathrm{ml}^{-1}\right)$ for $4 \mathrm{~h}$, thereby preventing extrusion of the second polar body, to optimize results. There were no differences in the ability of the different agents to support development of mouse oocytes to the blastocyst stage (Table 3).

\section{$\left[\mathrm{Ca}^{2+}\right]_{i}$-releasing activity in a single stallion spermatozoon}

As we wished to use eSF as a parthenogenetic agent in horse oocytes, but these are not readily available, the concentration of eSF that would provide $\left[\mathrm{Ca}^{2+}\right]_{i}$-releasing activity that most closely resembled that of a single stallion spermatozoon was first determined. B6D2F1 mouse oocytes at metaphase II were injected with one frozen-thawed sonicated stallion sperm head or eSF (1 or $5 \mu \mathrm{gl}^{-1}$ ), and the resulting $\left[\mathrm{Ca}^{2+}\right]_{i}$ profiles were compared. All mouse oocytes injected with a stallion spermatozoon displayed frequent $\left[\mathrm{Ca}^{2+}\right]_{i}$ oscillations that 
Table 4. Calcium-releasing activity of equine sperm extracts (eSF) and one stallion spermatozoon when microinjected into mouse oocytes

\begin{tabular}{|c|c|c|c|c|c|}
\hline & \multirow[b]{2}{*}{$n$} & \multirow{2}{*}{$\begin{array}{l}\text { Frequency (number of } \\
\text { oscillations in } 20 \mathrm{~min})^{*}\end{array}$} & \multirow{2}{*}{$\begin{array}{l}\text { Average duration of } \\
\text { transient }(\mathrm{min})\end{array}$} & \multicolumn{2}{|c|}{ Number of eggs oscillating } \\
\hline & & & & $\geqslant 40 \mathrm{~min}$ & $\geqslant 120 \mathrm{~min}$ \\
\hline \multicolumn{6}{|l|}{ eSF } \\
\hline$\left.1 \mu g \mu\right|^{-1}$ & 6 & $5 \pm 1.0^{\mathrm{a}}$ & $0.97 \pm 0.2$ & $4 / 6$ & $1 / 3$ \\
\hline$\left.5 \mu g \mu\right|^{-1}$ & 6 & $11 \pm 1.7^{\mathrm{b}}$ & $1.02 \pm 0.1$ & $6 / 6$ & $4 / 4$ \\
\hline ICSI & 8 & $11 \pm 1.7^{b}$ & $1.09 \pm 0.1$ & $8 / 8$ & $5 / 5$ \\
\hline
\end{tabular}

*Spike frequency was measured from $10 \mathrm{~min}$ to $30 \mathrm{~min}$ after microinjection or intracytoplasmic sperm injection (ICSI). ICSI: mouse oocytes were microinjected with the head of a single sonicated, frozen-thawed stallion spermatozoon by intracytoplasmic sperm injection.

Values are mean \pm SEM.

${ }^{\mathrm{ab}}$ Means within a column with different superscripts are significantly different $(P<0.05)$.

(a)

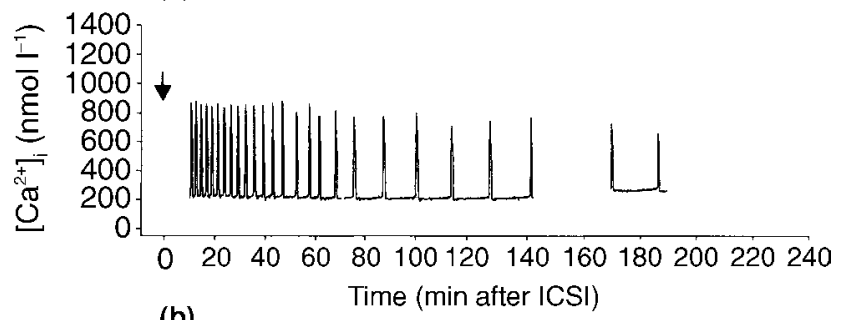

(b)

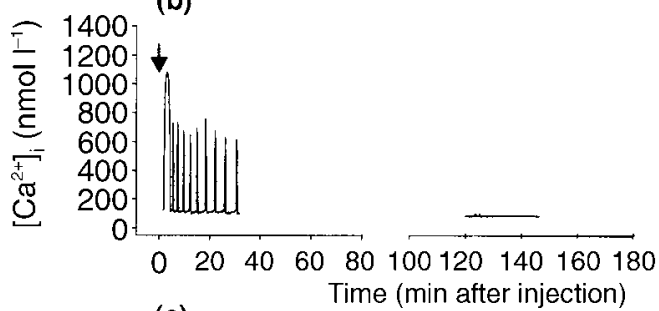

(c)

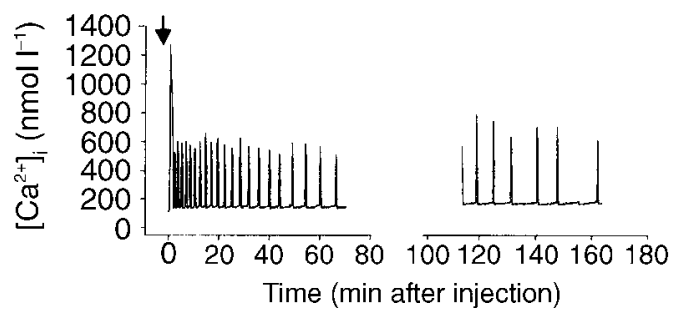

Fig. 3. Representative intracellular $\mathrm{Ca}^{2+}$ concentration $\left(\left[\mathrm{Ca}^{2+}\right]_{\mathrm{i}}\right)$ profiles for metaphase II mouse oocytes injected with (a) a single stallion sperm head (intracytoplasmic sperm injection; ICSI; $n=8$ ) or with (b) $1 \mu \mathrm{g}$ equine sperm extract (eSF) $\mu \mathrm{I}^{-1}(n=6)$ or (c) $5 \mu \mathrm{g}$ eSF $\mu \mathrm{I}^{-1}(n=6)$. Arrows indicate times of injection.

lasted for $>120 \mathrm{~min}$. The concentration of eSF that initiated oscillations with similar duration and frequency to those induced by a stallion spermatozoon was $5 \mu \mathrm{g} \mathrm{I}^{-1}$ (Fig. 3 and summarized in Table 4), a concentration ten times greater than the concentration needed to induce oscillations comparable to those initiated by a mouse spermatozoon. Therefore, $5 \mu \mathrm{g} \mathrm{eSF} \mu \mathrm{I}^{-1}$ was thought to most closely represent the amount of SF in a stallion spermatozoon and was used for subsequent microinjection of horse oocytes.
Effect of microinjection of eSF on $\left[\mathrm{Ca}^{2+}\right]_{i}$ oscillations and activation in horse oocytes

The ability of eSF to induce $\left[\mathrm{Ca}^{2+}\right]_{i}$ oscillations and activation in horse oocytes was investigated by using oocytes matured in vitro for 24 or $42 \mathrm{~h}$, as the optimal duration of maturation before fertilization in horse oocytes has not been well defined. Therefore, horse oocytes in both maturation groups ( 24 or $42 \mathrm{~h}$ ) were injected with $5 \mu \mathrm{g} \mathrm{eSF} \mu \mathrm{I}^{-1}$ and the resulting $\left[\mathrm{Ca}^{2+}\right]_{\mathrm{i}}$ responses were compared. Overall, 22 of 25 injected oocytes responded with $\left[\mathrm{Ca}^{2+}\right]_{i}$ oscillations (13 of 14 and 9 of 11, for the 24 and $42 \mathrm{~h}$ maturation groups, respectively). Representative $\left[\mathrm{Ca}^{2+}\right]_{i}$ profiles for 24 and $42 \mathrm{~h}$ in vitro matured oocytes are shown (Fig. 4) and the pattern of $\left[\mathrm{Ca}^{2+}\right]_{i}$ responses is summarized (Table 5). No differences in $\left[\mathrm{Ca}^{2+}\right]_{i}$ responses were observed between the two groups of oocytes. The initial $\left[\mathrm{Ca}^{2+}\right]_{i}$ spikes occurred every few minutes but then spikes occurred at longer intervals (Fig. 4); in most oocytes that were monitored for a prolonged period, $\left[\mathrm{Ca}^{2+}\right]_{i}$ oscillations lasted for between $60 \mathrm{~min}$ and $120 \mathrm{~min}$.

The $\left[\mathrm{Ca}^{2+}\right]_{i}$ oscillations initiated by injection of 5 $\mu \mathrm{g}$ eSF $\mu \mathrm{I}^{-1}$ induced normal activation of development. For example, when evaluated at 20-24 h after microinjection, eight of $13(61 \%)$ and 13 of $14(81 \%)$ oocytes matured for 24 and $42 \mathrm{~h}$, respectively, showed pronuclear formation (Fig. 5).

As for our previous results with mouse oocytes, microinjection of buffer alone or of sperm extracts with protein concentrations $<0.1 \mu \mathrm{g} \mu \mathrm{l}^{-1}$ into mare oocytes did not result in the initiation of $\left[\mathrm{Ca}^{2+}\right]_{i}$ oscillations or induce activation.

Effect of ICSI performed with one progressively motile fresh stallion spermatozoon on $\left[\mathrm{Ca}^{2+}\right]_{i}$ transients in in vitro matured horse oocytes

As eSF was able to induce consistent $\left[\mathrm{Ca}^{2+}\right]_{i}$ responses in horse oocytes, the pattern of sperm-induced $\left[\mathrm{Ca}^{2+}\right]_{i}$ 
(a)

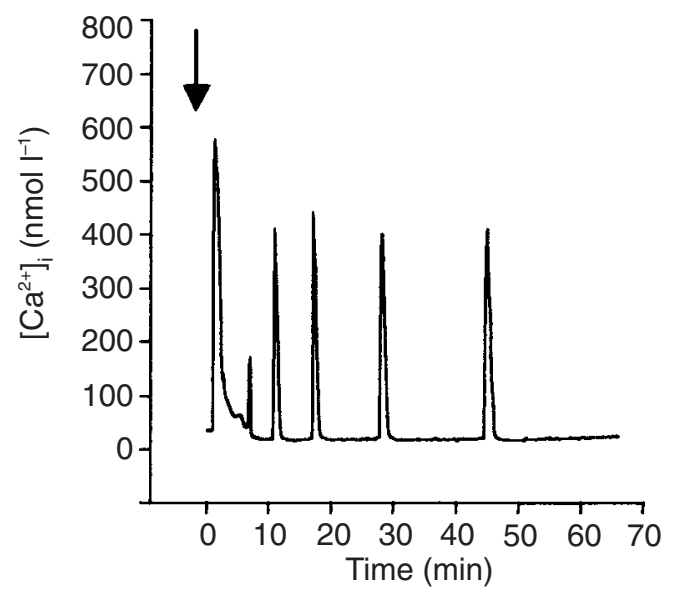

(b)

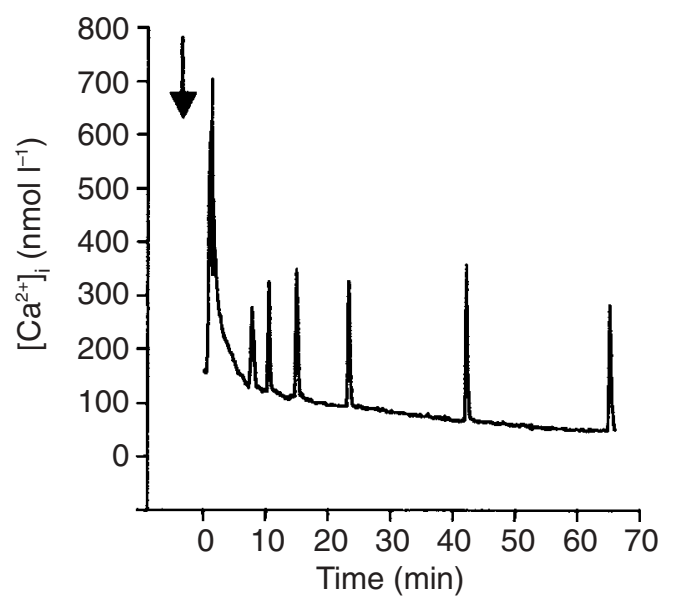

Fig. 4. Representative intracellular $\mathrm{Ca}^{2+}$ concentration $\left(\left[\mathrm{Ca}^{2+}\right]_{\mathrm{i}}\right)$ profiles for horse oocytes matured in vitro for (a) $24(n=13)$ or (b) $42 \mathrm{~h}(n=9)$ and microinjected with $5 \mu$ g equine sperm extract $\mu \mathrm{I}^{-1}$. Arrows indicate times of injection.

oscillations in horse oocytes was evaluated. In this experiment, $\left[\mathrm{Ca}^{2+}\right]_{i}$ monitoring was started within $30 \mathrm{~min}$ of sperm injection. ICSI did not consistently initiate fertilization-like $\left[\mathrm{Ca}^{2+}\right]_{i}$ transients, as only five of 13
$(38 \%)$ of the sperm-injected oocytes showed $\left[\mathrm{Ca}^{2+}\right]_{i}$ oscillations, and only two of these oocytes displayed responses that lasted for $>2 \mathrm{~h}$ (Fig. 6). In oocytes that showed $\mathrm{Ca}^{2+}$ responses, the average spike interval was approximately $40 \mathrm{~min}$ and the mean duration was 3 min. Despite the small percentage of oocytes displaying long lasting $\left[\mathrm{Ca}^{2+}\right]_{i}$ oscillations, six of ten $(58 \%)$ oocytes were activated when evaluated at 20-24 h after ICSI.

\section{Discussion}

The results of the present study demonstrate for the first time that horse oocytes respond to the injection of eSF with $\left[\mathrm{Ca}^{2+}\right]_{i}$ oscillations and activation. Furthermore, and more importantly, the ability of horse oocytes to display $\left[\mathrm{Ca}^{2+}\right]_{i}$ oscillations after sperm injection is demonstrated, strongly indicating that sperm-induced $\left[\mathrm{Ca}^{2+}\right]_{i}$ responses are probably an important event leading to oocyte activation in horses, as in all other mammalian species studied to date. The activity of eSF was initially tested using mouse oocytes as a model, as it is well recognized that heterologous sperm extracts can induce fertilization-like $\left[\mathrm{Ca}^{2+}\right]_{\mathrm{i}}$ responses and embryonic development in several species (Fissore et al., 1998; Knott et al., 2002), and partly also due to the difficulty in obtaining horse oocytes. Equine sperm extracts are capable of inducing $\left[\mathrm{Ca}^{2+}\right]_{\mathrm{i}}$ oscillations in mouse oocytes similar to those initiated by fertilization and injection of pSF (Fissore et al., 1992, 1998). Furthermore, injection of eSF was able to induce activation and development to the blastocyst stage in mouse oocytes at rates similar to those obtained with pSF and adenophostin. These results support the contention that the molecule responsible for oocyte activation is highly conserved among species.

The results of the present study demonstrate that a higher concentration of eSF than is needed to activate mouse oocytes was required to simulate the $\left[\mathrm{Ca}^{2+}\right]_{i}-$ releasing activity of one stallion spermatozoon. Therefore, a novel approach to estimate the SF activity present in one spermatozoon is presented. Previous studies have approximated the physiological concentrations of SF, referred to as one spermatozoon equivalent, on the basis

Table 5. Intracellular calcium concentration $\left(\left[\mathrm{Ca}^{2+}\right]_{\mathrm{i}}\right)$ transient data for metaphase II horse oocytes matured in vitro for 24 or $42 \mathrm{~h}$ and microinjected with $5 \mu \mathrm{g}$ equine sperm extracts (eSF) $\mu \mathrm{I}^{-1}$

\begin{tabular}{|c|c|c|c|c|c|c|}
\hline $\begin{array}{l}\text { Duration of } \\
\text { in vitro maturation }\end{array}$ & $n^{\mathrm{a}}$ & $\begin{array}{l}\text { Frequency (number of } \\
\text { oscillations in } 20 \mathrm{~min})^{b}\end{array}$ & $\begin{array}{c}\text { Transient } \\
\text { duration (min) }\end{array}$ & $\begin{array}{c}\text { Spike } \\
\text { amplitude }\end{array}$ & $\begin{array}{c}\text { Number of eggs } \\
\text { oscillating } \geqslant 60 \mathrm{~min}^{\mathrm{c}}\end{array}$ & $\begin{array}{c}\text { Activation to } \\
\text { pronuclear stage }(\%)^{d}\end{array}$ \\
\hline 71 & $13 / 14$ & $3.5 \pm 0.9^{c}$ & $1.3 \pm 0.1$ & $386.4 \pm$ & $8 / 8$ & $8 / 13(61)$ \\
\hline $42 \mathrm{~h}$ & $9 / 11$ & $3.2 \pm 0.5$ & $1.1 \pm 0.3$ & $306.6 \pm 99.8$ & $7 / 8$ & $13 / 16(81)$ \\
\hline
\end{tabular}

Data are mean \pm SE.

a Number of oocytes displaying $\left[\mathrm{Ca}^{2+}\right]_{i}$ responses out of number of oocytes microinjected with eSF.

${ }^{b}$ Number of spikes from $10 \mathrm{~min}$ to $30 \mathrm{~min}$ after injection.

${ }^{\mathrm{c}}$ Number of oocytes displaying $\left[\mathrm{Ca}^{2+}\right]_{i}$ responses out of number of oocytes monitored for $\geqslant 60 \mathrm{~min}$.

${ }^{d}$ Activation data include oocytes in which $\left[\mathrm{Ca}^{2+}\right]_{i}$ responses were not monitored due to insufficient fura- 2 or technical difficulties with the monitoring system. 

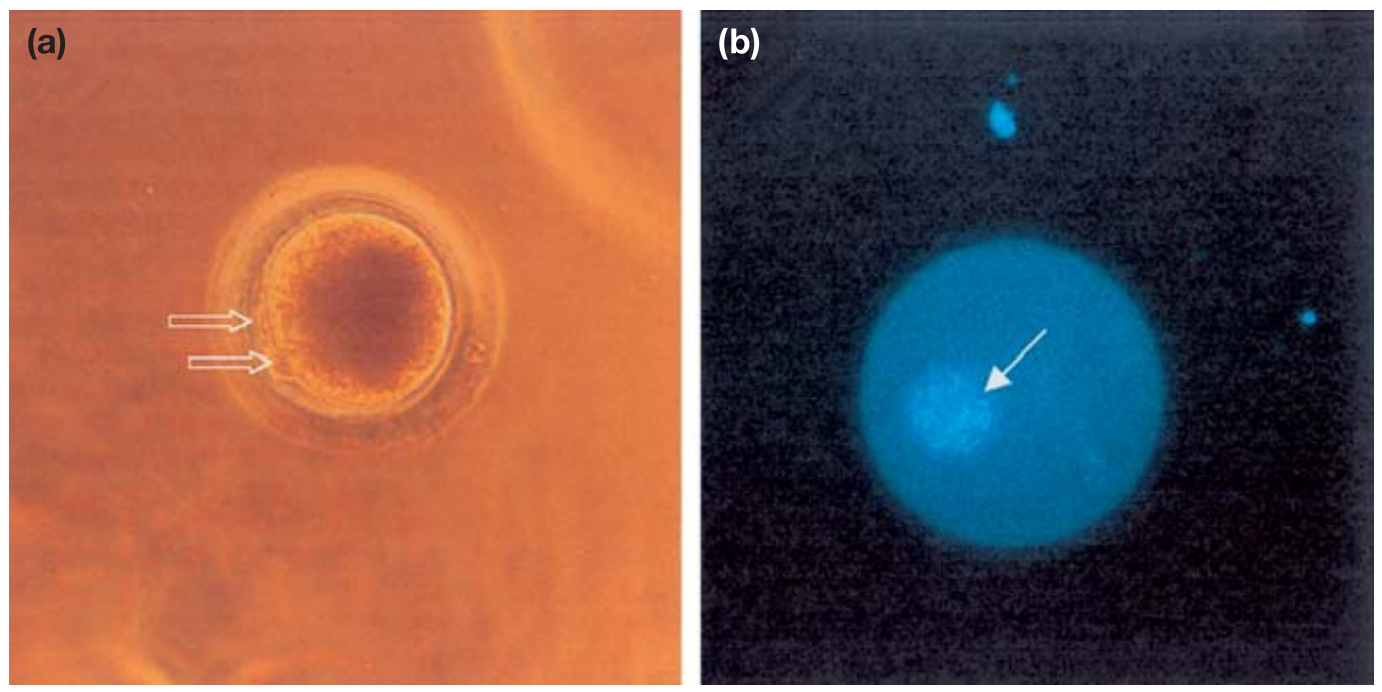

Fig. 5. Horse oocyte parthenogenetically activated by injection of stallion sperm extracts $\left(5 \mu \mathrm{g}\right.$ eSF $\left.\mu \mathrm{I}^{-1}\right)$ as evidenced by the presence of two polar bodies (open arrows) and one pronucleus (solid arrow). (a) Phase contrast microscopy. (b) After fixation and staining with Hoechst 33248.

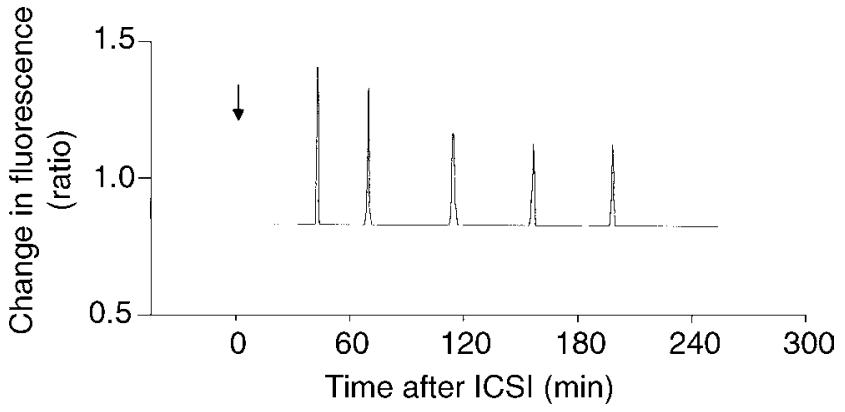

Fig. 6. Intracellular $\mathrm{Ca}^{2+}$ concentration $\left(\left[\mathrm{Ca}^{2+}\right]_{i}\right)$ profile for a horse oocyte injected with a single progressively motile stallion spermatozoon immobilized by piezoelectric pulses before injection. Only two oocytes of 13 oocytes displaying persistent $\left[\mathrm{Ca}^{2+}\right]_{\mathrm{i}}$ oscillations had long lasting $\left[\mathrm{Ca}^{2+}\right]_{i}$ oscillations. Arrow indicates time of intracytoplasmic sperm injection (ICSI). Fluorescence changes representing $\left[\mathrm{Ca}^{2+}\right]_{i}$ are given as ratios of $340 \mathrm{~nm}: 380 \mathrm{~nm}$ fluorescence.

of the amount of protein obtained from a certain number of spermatozoa in the ejaculate at the time of sperm extract preparation (Wu et al., 1998a). However, it is likely that part of the active protein is lost or inactivated during the preparation process and thus such comparisons may be largely inaccurate. In the present study, the amount of eSF capable of inducing oscillations in mouse oocytes equivalent to the responses induced in mouse oocytes by injection of one stallion spermatozoon was used; in the conditions in the present study this concentration of eSF was $5 \mu \mathrm{gl}^{-1}$. The concentration of eSF needed to induce $\left[\mathrm{Ca}^{2+}\right]_{i}$ oscillations comparable to those initiated by a mouse spermatozoon was $0.5 \mu \mathrm{g} \mu \mathrm{I}^{-1}$, indicating that a stallion spermatozoon may contain at least ten times more SF than a mouse spermatozoon.
On the basis of the above results, horse oocytes were microinjected with $5 \mu \mathrm{g} \operatorname{eSF} \mu \mathrm{I}^{-1}$ and thus it was presumed that the $\left[\mathrm{Ca}^{2+}\right]_{i}$ responses obtained closely resemble those at fertilization in horses. This assumption is of particular importance in this species, for which the pattern of $\left[\mathrm{Ca}^{2+}\right]_{i}$ Oscillations at fertilization has not been ascertained, and in which the low availability of oocytes for investigation and the technical difficulties linked to low rates of sperm penetration during in vitro fertilization have made the gathering of such data very challenging (Palmer et al., 1991; Hinrichs et al., 2002). The frequency of $\left[\mathrm{Ca}^{2+}\right]_{i}$ responses observed in equine oocytes on eSF microinjection closely resembled that reported for bovine oocytes at fertilization or when injected with appropriate concentrations of pSF (Fissore et al., 1992; Nakada et al., 1995; Nakada and Mizuno, 1998; Knott et al., 2002), thereby suggesting that the observed responses were physiological.

The $\left[\mathrm{Ca}^{2+}\right]_{i}$ transients observed in the present study by eSF-injected horse oocytes matured in vitro for 24 or $42 \mathrm{~h}$ were very consistent in amplitude, frequency and overall duration. This observation is particularly important as the optimal time for IVM of horse oocytes has not been well defined. In most reports addressing assisted reproductive techniques in horses, the oocytes are matured for a period ranging from $24 \mathrm{~h}$ to $44 \mathrm{~h}$ (Grøndahl et al., 1995; Hinrichs et al., 1995; Dell'Aquila et al., 1997; Li et al., 2000; Choi et al., 2001). Horse oocytes must be matured in vitro for at least $24 \mathrm{~h}$ to achieve significant rates of metaphase II stage oocytes (Hinrichs et al., 1993), but the optimal time for reaching full developmental competence is unknown. Studies in laboratory species demonstrate that immature oocytes, either at the germinal vesicle stage or before the metaphase II stage, show lower $\left[\mathrm{Ca}^{2+}\right]_{i}$ responses to 
parthenogenetic activation or fertilization (Shiraishi et al., 1995; Jones and Nixon, 2000). Similarly, only $16 \%$ (two of six; data not shown) of horse oocytes found in metaphase $\mathrm{I}$ at the time of staining responded with $\left[\mathrm{Ca}^{2+}\right]_{i}$ transients in the present study. In other species, this appears to be the result of changes in distribution and sensitivity of the $\mathrm{IP}_{3}$ receptor that occur during oocyte maturation (Shiraishi et al., 1995; Fissore et al., 1999), although whether this is the case in horse oocytes is not known.

Ageing of oocytes also limits responsiveness. Recent evidence in mice shows that oocytes aged in vitro for prolonged periods lose their ability to display long lasting $\left[\mathrm{Ca}^{2+}\right]_{i}$ oscillations after microinjection of sperm extracts or fertilization, and may undergo apoptosis instead of the expected normal progression of embryonic development (Gordo et al., 2000, 2002). The results of the present study indicate that metaphase II horse oocytes have already gained the ability to respond with $\left[\mathrm{Ca}^{2+}\right]_{i}$ transients after $24 \mathrm{~h}$, and that this ability is not reduced after $42 \mathrm{~h}$ of IVM. Future studies should investigate the relationship between the ability of horse oocytes to display $\left[\mathrm{Ca}^{2+}\right]_{\mathrm{i}}$ oscillations, time of maturation and developmental fate.

In the present study, $88 \%$ of eSF-microinjected horse oocytes responded with $\left[\mathrm{Ca}^{2+}\right]_{i}$ transients, and $71 \%$ of these oocytes showed pronuclear formation within 20-24 h after eSF injection, a clear sign of activation. These results may actually underrepresent the true rates of activation, as the oocytes in the present study had been injected with fura- 2 and were exposed to UV light for prolonged periods, all of which compromise pronuclear formation. Notably, the high rates of $\left[\mathrm{Ca}^{2+}\right]_{i}$ responses and activation obtained with eSF in the present study contrast with the variable, and mostly low, rates of activation and development reported for ICSI (ranging from 0\% to 71\%; Dell'Aquila et al., 1997; Li et al., 2000; Choi et al., 2002b). Importantly, the result of the present study showing that only a small percentage of horse oocytes are able to respond with $\left[\mathrm{Ca}^{2+}\right]_{\mathrm{i}}$ oscillations to sperm injection indicates that the low rates of activation and embryonic development may be related, at least in part, to an inadequate activation stimulus caused by the lack of initiation of $\left[\mathrm{Ca}^{2+}\right]_{\mathrm{i}}$ oscillations. This defect may arise from a presumed inability of horse oocytes to promote release of the factor from the injected spermatozoon, or, alternatively, it may be the consequence of a deficient step in the activation or processing of the factor once released. Moreover, it is possible that species-specific differences in $\mathrm{IP}_{3}$ receptor sensitivity in oocytes, or decreased ability of in vitro matured oocytes, may contribute, at least in part, to the decreased responsiveness of horse oocytes to the injected spermatozoon. All of these possibilities require further investigation.

In conclusion, it is shown for the first time that horse oocytes are capable of displaying $\left[\mathrm{Ca}^{2+}\right]_{i}$ transients in response to injection of sperm extracts, and, to a lesser degree, after ICSI. This finding proves three important points: (i) that stallion spermatozoa contain the molecule or molecules responsible for initiation of $\left[\mathrm{Ca}^{2+}\right]_{\mathrm{i}}$ oscillations in oocytes; (ii) more importantly, that the mechanism leading to oocyte activation is $\left[\mathrm{Ca}^{2+}\right]_{\mathrm{i}}-$ dependent in horse oocytes, similar as it is in other species; and (iii) that the pattern of $\left[\mathrm{Ca}^{2+}\right]_{i}$ oscillations displayed by oocytes in the present study is comparable to that described in bovine oocytes at fertilization. At present, it is only possible to speculate that horse oocytes may display a similar frequency of $\left[\mathrm{Ca}^{2+}\right]_{i}$ transients under conventional fertilization. Further studies should investigate the reasons that preclude consistent $\left[\mathrm{Ca}^{2+}\right]_{\mathrm{i}}$ responses in horse oocytes submitted to ICSI, which may lead to mechanisms to improve the success rate of this assisted reproduction tool in horses and other domestic species.

This work was funded by a Healey Endowment Grant at the University of Massachusetts to S. J. Bedford and R. A. Fissore; it was also supported by funds provided by grants from the USDA (02-2078) and USDA/Hatch grant to R. A. Fissore, a Lalor foundation fellowship to M. Kurokawa, and the Link Equine Research Endowment (Texas A\&M University). The authors would like to acknowledge C. He, H. Wu and T. Jellerette for their help with the experimental techniques used in this study, and J. Smyth for useful comments on the manuscript. The authors would also like to thank B. Hanlon, and the staff and students at the Hadley Farm, University of Massachusetts, for their assistance with semen collection from stallions. The authors are grateful to L. Love and Y. Ho Choi for their assistance in shipping mare oocytes for this research.

\section{References}

Carroll J (2001) The initiation and regulation of $\mathrm{Ca}^{2+}$ signaling at fertilization in mammals Seminars in Cell and Developmental Biology 12 37-43

Choi YH, Love CC, Varner DD, Thompson JA and Hinrichs K (2001) Activation of cumulus-free equine oocytes: effects of maturation medium, calcium ionophore concentration and duration of cycloheximide exposure Reproduction 122 177-183

Choi YH, Love CC, Chung YG, Varner DD, Westhusin ME, Burghardt RC and Hinrichs K (2002a) Production of nuclear transfer horse embryos by Piezo-driven injection of somatic cell nuclei and activation with stallion sperm cytosolic extract Biology of Reproduction 67 561-567

Choi YH, Love CC, Varner DD, Brinsko S and Hinrichs K (2002b) Developmental competence of in vivo- and in vitro-matured equine oocytes fertilized by intracytoplasmic sperm injection with fresh or frozen-thawed spermatozoa Reproduction 123 455-465

Chung JT, Keefer CL and Downey BR (2000) Activation of bovine oocytes following intracytoplasmic sperm injection (ICSI) Theriogenology $\mathbf{5 3}$ 1273-1284

Collas P, Fissore R, Robl JM and Sullivan EJ (1993) Electrically induced calcium elevation, activation, and parthenogenetic development of bovine oocytes Molecular Reproduction and Development 34 212-223

Cox LJ, Larman MG, Saunders CM, Hashimoto K, Swann K and Lai FA (2002) Sperm phospholipase Czeta from humans and cynomolgus monkeys triggers $\mathrm{Ca}^{2+}$ oscillations, activation and development in mouse oocytes Reproduction 124 611-623

Dell'Aquila ME, Cho YS, Minoia P, Traina V, Lacalandra GM and Maritato $\mathbf{F}$ (1997) Effects of follicular fluid supplementation of in-vitro maturation 
medium on the fertilization and development of equine oocytes after in-vitro fertilization or intracytoplasmic sperm injection Human Reproduction 12 2766-2772

Fissore RA and Robl JM (1992) Intracellular $\mathrm{Ca}^{2+}$ responses of rabbit oocytes to electrical stimulation Molecular Reproduction and Development 32 9-16

Fissore RA and Robl JM (1993) Sperm, inositol triphosphate, and thimerosalinduced intracellular $\mathrm{Ca}^{2+}$ elevations in rabbit eggs Developmental Biology 159 122-130

Fissore RA, Dobrinsky JR, Balise JJ, Duby RT and Robl JM (1992) Patterns of intracellular $\mathrm{Ca}^{2+}$ concentration in fertilized bovine oocytes Biology of Reproduction 47 960-969

Fissore RA, Pinto-Correia C and Robl JM (1995) Inositol triphosphateinduced calcium release in the generation of calcium oscillations in bovine eggs Biology of Reproduction 53 766-774

Fissore RA, He CL and Vande Woude GF (1996) Potential role of mitogenactivated protein (MAP) kinase during meiosis resumption in bovine oocytes Biology of Reproduction 55 1261-1270

Fissore RA, Gordo AC and Wu H (1998) Activation of development in mammals: is there a role for a sperm cytosolic factor? Theriogenology 49 43-52

Fissore RA, Longo FJ, Anderson E, Parys JB and Ducibella T (1999) Differential distribution of inositol triphosphate receptor isoforms in mouse oocytes Biology of Reproduction 60 49-57

Gordo AC, Wu H, He CL and Fissore RA (2000) Injection of sperm cytosolic factor into mouse metaphase II oocytes induces different developmental fates according to the frequency of $\left[\mathrm{Ca}^{2+}\right]_{i}$ oscillations and oocyte age Biology of Reproduction 62 1370-1379

Gordo AC, Rodrigues P, Kurokawa M, Jellerette T, Exley GE, Warner C and Fissore R (2002) Intracellular calcium oscillations signal apoptosis rather than activation in in vitro aged mouse eggs Biology of Reproduction $\mathbf{6 6}$ $1828-1837$

Grøndahl C, Høst T, Brück I, Viuff D, Bézard J, Fair T, Greve T and Hyttel P (1995) In vitro production of equine embryos Biology of Reproduction Monograph Series 1 299-307

Hinrichs K and Schmidt AL (2000) Meiotic competence in horse oocytes: interactions among chromatin configuration, follicle size, cumulus morphology, and season Biology of Reproduction 62 1402-1408

Hinrichs K, Schmidt AL, Friedman PP, Selgrath JP and Martin MG (1993) In vitro maturation of horse oocytes: characterization of chromatin configuration using fluorescence microscopy Biology of Reproduction $48363-370$

Hinrichs K, Schmidt AL and Selgrath JP (1995) Activation of horse oocytes Biology of Reproduction Monograph Series 1 319-324

Hinrichs K, Love CC, Brinsko SP, Choi YH and Varner DD (2002) In vitro fertilization of in vitro-matured equine oocytes: effect of maturation medium, duration of maturation, and sperm calcium ionophore treatment, and comparison with rates of fertilization in vivo after oviductal transfer Biology of Reproduction 67 256-262

Jones KT and Nixon VL (2000) Sperm-induced $\mathrm{Ca}^{2+}$ oscillations in mouse oocytes and eggs can be mimicked by photolysis of caged inositol 1,4,5-triphosphate: evidence to support a continuous low level production of inositol 1,4,5-triphosphate during mammalian fertilization Developmental Biology 225 1-12

Kato H, Seidel GE, Squires EL and Wilson JM (1997) Treatment of equine oocytes with A23187 after intracytoplasmic sperm injection Equine Veterinary Journal Supplement 25 51-53

Kimura Y and Yanagimachi R (1995) Intracytoplasmic sperm injection in the mouse Biology of Reproduction 52 709-720

Kline D and Kline JT (1992) Repetitive calcium transients and the role of calcium in exocytosis and cell cycle activation in the mouse egg Developmental Biology 149 80-89

Knott JG, Poothapillai K, Wu H, He CL, Fissore RA and Robl JM (2002) Porcine sperm factor supports activation and development of bovine nuclear transfer embryos Biology of Reproduction 66 1095-1103

Laemmli UK (1970) Cleavage of structural proteins during the assembly of the head of bacteriophage T4 Nature 227 680-685
Li X, Morris LHA and Allen WR (2000) Effects of different activation treatments on fertilization of horse oocytes by intracytoplasmic sperm injection Journal of Reproduction and Fertility 119 253-260

Li X, Morris LH-A and Allen WR (2001) Influence of co-culture during maturation on the developmental potential of equine oocytes fertilized by intracytoplasmic sperm injection (ICSI) Reproduction 121 925-932

Machaty Z, Bonk AJ, Kuhholzer B and Prather RS (2000) Porcine oocyte activation induced by a cytosolic sperm factor Molecular Reproduction and Development 57 290-295

Nakada K and Mizuno J (1998) Intracellular calcium responses in bovine oocytes induced by spermatozoa and by reagents Theriogenology $\mathbf{5 0}$ 269-282

Nakada K, Mizuno J, Shiraishl K, Endo K and Miyazaki S (1995) Initiation, persistence, and cessation of the series of intracellular $\mathrm{Ca}^{2+}$ responses during fertilization of bovine oocytes Journal of Reproduction and Development 41 77-84

Ozil J-P and Huneau D (2001) Activation of rabbit oocytes: the impact of the $\mathrm{Ca}^{2+}$ signal regime on development Development 128 917-928

Palmer E, Bézard J, Magistrini M and Duchamp G (1991) In vitro fertilization in the horse. A retrospective study Journal of Reproduction and Fertility Supplement 44 375-384

Presicce GA and Yang X (1994) Parthenogenetic development of bovine oocytes matured in vitro for $24 \mathrm{hr}$ and activated by ethanol and cycloheximide Molecular Reproduction and Development $\mathbf{3 8}$ 380-385

Sato Y, Miyazaki S, Shikano T, Mitsuhashi N, Takeuchi H, Mikoshiba K and Kuwabara Y (1998) Adenophostin, a potent agonist of the inositol 1,4,5-triphosphate receptor, is useful for fertilization of mouse oocytes injected with round spermatids leading to normal offspring Biology of Reproduction 58 867-873

Saunders CM, Larman MG, Parrington J, Cox LJ, Royse J, Blayney LM, Swann K and Lai FA (2002) PLCל: a sperm-specific trigger of $\mathrm{Ca}^{2+}$ oscillations in eggs and embryo development Development 1293533 3544

Shiraishi K, Okada A, Shirakawa H, Nakanishi S, Mikoshiba K and Miyazaki S (1995) Developmental changes in the distribution of the endoplasmic reticulum and inositol 1,4,5-triphosphate receptors and the spatial pattern of $\mathrm{Ca}^{2+}$ release during maturation of hamster oocytes Developmental Biology 170 594-606

Stice SL and Robl JM (1990) Activation of mammalian oocytes by a factor obtained from rabbit sperm Molecular Reproduction and Development 25 272-280

Swann K (1996) Soluble sperm factors and $\mathrm{Ca}^{2+}$ release in eggs at fertilization Reviews of Reproduction 133-39

Whitaker M (1996) Control of meiotic arrest Reviews of Reproduction 1 127-135

Wu H, He CL and Fissore RA (1997) Injection of porcine sperm factor triggers calcium oscillations in mouse oocytes and bovine eggs Molecular Reproduction and Development 46 176-189

Wu H, He CL, Jehn B, Black SJ and Fissore RA (1998a) Partial characterization of the calcium-releasing activity of porcine sperm cytosolic extracts Developmental Biology 203 369-381

Wu H, He CL and Fissore RA (1998b) Injection of a porcine sperm factor induces activation of mouse eggs Molecular Reproduction and Development 49 37-47

Wu H, Smyth J, Luzzi V, Fukami K, Takenawa T, Black SL, Allbritton NL and Fissore RA (2001) Sperm factor induces intracellular free calcium oscillations by stimulating the phophoinositide pathway Biology of Reproduction 64 1338-1349

Received 7 April 2003.

First decision 2 June 2003.

Revised manuscript received 2 July 2003.

Accepted 4 July 2003. 